\title{
Persistent urethritis and prostatitis due to Trichomonas vaginalis: A case report
}

\author{
Alireza Abdolrasouli BSc MSPH MSc ${ }^{1}$, Abolghasem Amin PhD², Manouchehr Baharsefat PhD²,
} Azita Roushan $\mathrm{BSc}^{2}$, Shamseddin Mofidi MD PhD ${ }^{3}$

\begin{abstract}
A Abdolrasouli, A Amin, M Baharsefat, A Roushan, S Mofidi. Persistent urethritis and prostatitis due to Trichomonas vaginalis: A case report. Can J Infect Dis Med Microbiol $2007 ; 18(5): 308-310$.
\end{abstract}

The present report describes a case of persistent urethritis accompanied by prostatitis due to Trichomonas vaginalis in a young male patient. The importance of the laboratory diagnosis of trichomoniasis in persistent or recurrent urethritis (ie, testing samples from multiple sites) is highlighted, with the aim of improving the clinical recognition of this pathogen.

\section{Une urétrite persistante et une prostatite causées par une infection à Trichomonas vaginalis : Rapport de cas}

\begin{abstract}
Le présent rapport décrit un cas d'urétrite persistante accompagnée d'une prostatite, causées par une infection à Trichomonas vaginalis chez un jeune patient de sexe masculin. On souligne l'importance du diagnostic de trichomonase en laboratoire en cas d'urétrite persistante ou récurrente (c'est-à-dire par des tests d'échantillons de multiples foyers) afin d'améliorer la constatation clinique de ce pathogène.
\end{abstract}

Key Words: Persistent urethritis; Prostatitis; Trichomonas vaginalis

$\mathrm{T}$ ichomoniasis is highly prevalent worldwide and is associated with urethritis (1-3) and prostatitis $(4,5)$ in men. Moreover, infection with Trichomonas vaginalis (TV) may increase the risk of HIV acquisition; some studies have associated TV infection with elevated seminal HIV RNA levels in men with HIV infection and symptomatic urethritis $(2,6,7)$. However, the importance of trichomoniasis in men is poorly understood, in part, due to difficulties in the diagnosis of the infection.

Detection of TV in men has traditionally been based on wet mount microscopy or culture of a single specimen, through either a urethral swab or a urine sediment. Although microscopic examination of the saline wet mount or culture has poor sensitivity (ranging from $60 \%$ to $80 \%$ ), they are still used as routine diagnostic tests for TV in many laboratories (3). A case of persistent urethritis with prostatitis due to TV, which was diagnosed by direct microscopy and cultivation of samples from multiple sites, is reported.

\section{CASE PRESENTATION}

A 26-year-old heterosexual man presented with a six-month history of persistent urethritis. He complained of urethral discharge, dysuria and a recent onset of perineal and ejaculatory pain. He had already been treated with multiple antibiotics, including ciprofloxacin, doxycycline, tetracycline and erythromycin, during his four previous visits to different clinicians. He had not received any metronidazole due to all previous negative investigations for TV on urethral and urine samples. He denied any extramarital sexual partners since his marriage one month ago, but acknowledged three casual female partners before that. He was using condoms with his wife for contraception. No information was available concerning clinical or laboratory follow-ups on any of his female contacts, including his wife.

A physical examination revealed scanty mucoid urethral discharge. There was no evidence of inguinal adenopathy, genital lesions or intrascrotal abnormalities. Three urethral specimens were obtained using calcium alginate swabs. The first swab was used to make a Gram stain preparation and to inoculate chocolate agar and New York City medium for the isolation of Neisseria gonorrhoeae. The second swab was used for detection of Chlamydia trachomatis by direct immunofluorescence assay. Wet mount microscopy and inoculation of modified Diamond's medium were performed on the third urethral swab to detect TV.

After the physical examination, the patient was requested to provide $10 \mathrm{~mL}$ to $20 \mathrm{~mL}$ of first-voided and midstream urine as part of the four-glass localization test previously described by Meares and Stamey (8). The patient then underwent prostatic massage and his expressed prostatic secretions were collected. Immediately after his prostatic massage, the patient collected $10 \mathrm{~mL}$ to $15 \mathrm{~mL}$ of urine. For all urine samples, $10 \mathrm{~mL}$ of urine was centrifuged at $1500 \mathrm{~g}$ for $10 \mathrm{~min}$ and $50 \mu \mathrm{L}$ of urine sediment was used to inoculate the TV culture bottles. Mycoplasma and ureaplasma culture media were inoculated using $50 \mu \mathrm{L}$ of firstvoided urine sediment separately. Finally, the patient was asked to provide a semen specimen for TV culture. The semen was allowed to liquefy at room temperature for approximately $1 \mathrm{~h}$ before processing. The liquefied semen was centrifuged at $2000 \mathrm{~g}$ for $10 \mathrm{~min}$, and approximately $50 \mu \mathrm{L}$ of sediment was used to

\footnotetext{
${ }^{1}$ Clinical Research Unit, Department of Infectious Tropical Diseases, London School of Hygiene Eु Tropical Medicine, London, United Kingdom;

${ }^{2}$ Department of Clinical Microbiology, Marie-Curie Medical Institute; ${ }^{3}$ Department of Clinical Microbiology, Mehr Hospital, Tehran, Iran Correspondence: Alireza Abdolrasouli, Clinical Microbiology Department, Pathology Centre, Hammersmith Hospital NHS trust, Du Cane Road,

London W12 OHS, United Kingdom. Telephone 44-0208-383-2060, fax 44-0208-383-5824, e-mail AAbdolrasouli@hhnt.nhs.uk

Received for publication October 2, 2006. Accepted February 21, 2007
} 
inoculate the last TV culture bottle as previously described by Kaydos-Danniels et al (9).

The Gram-stained urethral exudate showed more than 15 polymorphonuclear leukocytes (PMNLs) per oil immersion field and there was no evidence of intracellular Gram-negative diplococci. The direct immunofluorescence test for $\mathrm{C}$ trachomatis was negative. After $48 \mathrm{~h}$ of incubation at $37^{\circ} \mathrm{C}$ in $5 \%$ atmospheric $\mathrm{CO}_{2}$, no $\mathrm{N}$ gonorrhoeae strains were isolated. Cultures for Mycoplasma genitalium and Ureaplasma urealyticum were negative after five days. Direct examination of expressed prostatic secretions revealed 10 PMNLs to 15 PMNLs per high power field (original magnification $\times 400$ ) with few clumps, indicating prostate infection and inflammation. Wet-mount microscopy of all collected samples was negative for mobile trichomonad trophozoites, except for urine sediment after prostate massage. The first two Diamond's bottles that were inoculated by urethral swab and first-catch urine sediment, respectively, yielded negative results. TV trophozoites were observed in the third, fourth and fifth bottles, which were inoculated by prostate secretions, postprostate massage urine sediment and semen sample, respectively. All TV cultures were checked on days 2, 5 and 7 after inoculation. Interestingly, all culture bottles were negative until day 5 , when the first positive culture was found. Table 1 compares the results of direct microscopic examination of wet mounts and cultures based on different sampling sites.

The patient was diagnosed with TV infection and treated with $500 \mathrm{mg}$ metronidazole twice daily for seven days. He returned to the clinic for a follow-up three weeks after his first visit. The urethral discharge disappeared by day 3 of treatment and he acknowledged that his dysuria, perineal and ejaculatory pain had all completely resolved. Although follow-up cultures were suggested for test of cure, the patient rejected any additional investigations and did not return for further medical care. We did not have the opportunity to establish any TV investigations on vaginal samples from the patient's wife or his previous sexual partners.

\section{DISCUSSION}

Persistent or recurrent urethritis develops in a small proportion of men who suffer from nongonococcal urethritis (NGU); TV probably accounts for only a minority of these cases $(9,10)$. Clinical and laboratory diagnosis of trichomoniasis is more complicated in male patients (11). Although urethral swabs are usually considered to be the best specimen to diagnose TV infections in men, addition of other samples, such as urine or semen, increases the sensitivity of results. In addition, testing of only one specimen (even urethral swab) may lead to an underdiagnosis of the disease $(9,11)$. This is mainly due to the fact that Trichomonas can infect multiple sites of the male genitourinary tract, and in practice, it is possible to find organisms in one specimen but not in another when testing samples from the same individual. Alternatively, the number of organisms in male specimen cultures is very small and this number usually does not increase over the incubation period. Data from Wong et al (12) suggest that the prostate gland may be involved in persistent or recurrent urethritis, especially among men with negative urethral cultures and, in this condition, a prostatic focus could serve as a source of urethral infection. In conditions in which the cultivation of multiple samples is necessary to diagnose trichomoniasis, using highly sensitive nucleic acid amplification tests, such as polymerase chain reaction, may be sufficient to detect trichomonads in a single sample (9).
TABLE 1

Comparison of the results of wet-mount microscopy, culture and the number of polymorphonuclear leukocytes (PMNLs) from different sample sources

\begin{tabular}{|c|c|c|c|c|c|c|}
\hline \multirow[b]{2}{*}{$\begin{array}{l}\text { Test } \\
\text { results }\end{array}$} & \multicolumn{6}{|c|}{ Sample source } \\
\hline & $\begin{array}{l}\text { Urethral } \\
\text { swab }\end{array}$ & $\begin{array}{l}\text { First- } \\
\text { catch } \\
\text { urine }\end{array}$ & $\begin{array}{l}\text { Mid- } \\
\text { stream } \\
\text { urine* }^{*}\end{array}$ & $\begin{array}{c}\text { Expressed } \\
\text { prostate } \\
\text { secretions }\end{array}$ & $\begin{array}{c}\text { Urine after } \\
\text { prostate } \\
\text { massage }\end{array}$ & Semen \\
\hline $\begin{array}{l}\text { Wet mount } \\
\text { microscopy }\end{array}$ & -ve & $-v e$ & NA & $-v e$ & $+\mathrm{ve}$ & $-v e$ \\
\hline Culture & $-v e$ & $-v e$ & NA & $+\mathrm{ve}$ & $+\mathrm{ve}$ & $+\mathrm{ve}$ \\
\hline$(\mathrm{PMNLs} / \mathrm{hpf})^{\dagger}$ & $\dagger^{\dagger}>20$ & $15-20$ & $1-3$ & $10-15$ & $15-20$ & $1-3$ \\
\hline
\end{tabular}

*The midstream urine sample was only tested for the presence of PMNLs to exclude the possibility of urinary tract infection; the number of PMNLs/high power field (hpf) (original magnification $\times 400$ ) was counted from the sediments of first-catch, midstream and postprostate massage urine samples, while urethral swab expressed prostate secretions and semen samples were examined directly without concentration. -ve Negative; +ve Positive; NA Not applicable

TV has been reported in $1 \%$ to $17 \%$ of patients with NGU, and its relative importance in men with genitourinary infections depends on the prevalence of the infection within the community (1). In fact, men complaining of urethral discharge who sought treatment for NGU would currently be treated empirically. Current first-line recommendations (doxycycline $100 \mathrm{mg}$ orally twice daily for seven days or azithromycin $1 \mathrm{~g}$ orally in a single dose) do not cover treatment for TV infection $(10,13)$. For NGU that fails to respond to initial therapy, several alternatives may be considered. Metronidazole ( $2 \mathrm{~g}$ orally in a single dose or $500 \mathrm{mg}$ orally twice a day for seven days) plus azithromycin ( $1 \mathrm{~g}$ orally in a single dose) or erythromycin (500 mg orally four times daily for seven days) are the current recommended regimens (13). Woolley et al (14) argued that the addition of metronidazole therapy did not significantly affect the number of persistent urethritis cases or the relapse of patients with NGU. However, Price et al (15) showed that the addition of metronidazole to the syndromic management of male urethritis, in places where trichomoniasis is common, can not only eliminate the infection but may also help to reduce the transmission of HIV.

There is no consensus of opinion in the management of prostatitis caused by TV. In one study (16), two weeks of metronidazole ( $250 \mathrm{mg}$ twice daily) was used to treat chronic TV prostatitis. Skerk et al (17) demonstrated that TV eradication and clinical cure in patients with chronic prostatitis did not significantly differ with regard to the administered dose of metronidazole (three doses of $500 \mathrm{mg}$, for either seven or 14 days). We assumed that in our patient, the concurrent treatment of his partner(s) was unlikely. Our patient was treated with $500 \mathrm{mg}$ metronidazole twice daily for seven days because there is some evidence to suggest that the failure rate of a single dose is higher if partners are not treated simultaneously (18). Moreover, due to the recent onset of prostatitis in our patient, we did not put him under a 'chronic TV prostatitis' category and, therefore, neither a higher dose of metronidazole nor prolonged regimens were prescribed for him. Although his signs and symptoms completely subsided after treatment, we were unfortunately unable to prove TV eradication because no follow-up cultures were conducted.

Young men with persistent or recurrent NGU apparently represent a high-risk group for TV infection. These patients are subjected to repeated diagnostic evaluation and, although 
no infectious etiology has been found, they are often empirically treated with multiple courses of antibiotics. The present case highlights the importance and necessity of performing accurate diagnostic procedures in the case of persistent or recurrent urethritis. Collection of multiple specimens from different sites may increase the sensitivity of testing for TV in male patients with negative results by routine investigative methods.

ACKNOWLEDGEMENTS: The authors wish to express their sincere gratitude to Professor David Mabey of the London School of Hygiene \& Tropical Medicine and Dr Richard Lau of St George's Healthcare NHS Trust (London, UK), GenitoUrinary Medicine (GUM) clinic for their advice and comments on the present manuscript.

\section{REFERENCES}

1. Krieger JN, Jenny C, Verdon M, et al. Clinical manifestations of trichomoniasis in men. Ann Intern Med 1993;118:844-9.

2. Hobbs MM, Kazembe P, Reed AW, et al. Trichomonas vaginalis as a cause of urethritis in Malawian men. Sex Transm Dis 1999;26:381-7.

3. Krieger JN, Verdon M, Siegel N, Critchlow C, Holmes KK. Risk assessment and laboratory diagnosis of trichomoniasis in men. J Infect Dis 1992;166:1362-6.

4. Petrin D, Delgaty K, Bhatt R, Garber G. Clinical and microbiological aspects of Trichomonas vaginalis. Clin Microbiol Rev 1998;11:300-17.

5. Ohkawa M, Yamaguchi K, Tokunaga S, Nakashima T, Fujita S. The incidence of Trichomonas vaginalis in chronic prostatitis patients determined by culture using a newly modified liquid medium. J Infect Dis 1992;166:1205-6.

6. Sorvillo F, Kerndt P. Trichomonas vaginalis and amplification of HIV-1 transmission. Lancet 1998;351:213-4.

7. Cohen MS, Hoffmann IF, Royce RA, et al. Reduction of concentration of HIV-1 in semen after treatment of urethritis:
Implications for prevention of sexual transmission of HIV-1. AIDSCAP Malawi Research Group. Lancet 1997;349:1868-73.

8. Meares EM, Stamey TA. Bacteriologic localization patterns in bacterial prostatitis and urethritis. Invest Urol 1968;5:492-518.

9. Kaydos-Danniels SC, Miller WC, Hoffmann I, et al. The use of specimens from various genitourinary sites in men, to detect Trichomonas vaginalis infection. J Infect Dis 2004;189:1926-31.

10. Fox KK, Cohen MS. Sexually transmitted diseases: Gonococcal, chlamydial and mycoplasma urethritis. In: Cohen J, Powderly WG, eds. Infectious Diseases, 2nd edn. Spain: Mosby, 2004.

11. Krieger JN. Trichomoniasis in men: Old issues and new data. Sex Transm Dis 1995;22:83-96.

12. Wong ES, Hooton TM, Hill CC, McKevitt M, Stamm WE. Clinical and microbiological features of persistent or recurrent nongonococcal urethritis in men. J Infect Dis 1988;158:1098-101.

13. Centers for Disease Control and Prevention. Sexually transmitted diseases treatment guidelines 2006.

<http://www.cdc.gov/std/treatment/2006/toc.htm> (Version current at May 28, 2007).

14. Woolley PD, Kinghorn GR, Talbot MD, Duerden BI. Efficacy of combined metronidazole and triple tetracycline therapy in the treatment of non-gonococcal urethritis. Int J STD AIDS 1990;1:35-7.

15. Price MA, Zimba D, Hoffmann IF, et al. Addition of treatment for trichomoniasis to syndromic management of urethritis in Malawi: A randomized clinical trail. Sex Transm Dis 2003;30:516-22. (Erratum in 2004;31:516).

16. Ohkawa M, Yamaguchi K, Tokunaga S, Nakashima T, Fujita S. The incidence of Trichomonas vaginalis in chronic prostatitis patients determined by culture using a newly modified liquid medium. J Infect Dis 1992;166:1205-6.

17. Skerk V, Schonwald S, Granic J, et al. Chronic prostatitis caused by Trichomonas vaginalis - diagnosis and treatment. J Chemother 2002;14:537-8.

18. Thin RN, Symonds MA, Booker R, Cook S, Langlet F.

Double-blind comparison of a single dose and a five-day course of metronidazole in the treatment of trichomoniasis. Br J Vener Dis $1979 ; 55: 354-6$. 


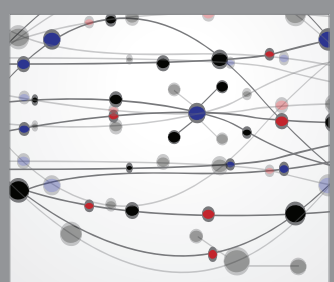

The Scientific World Journal
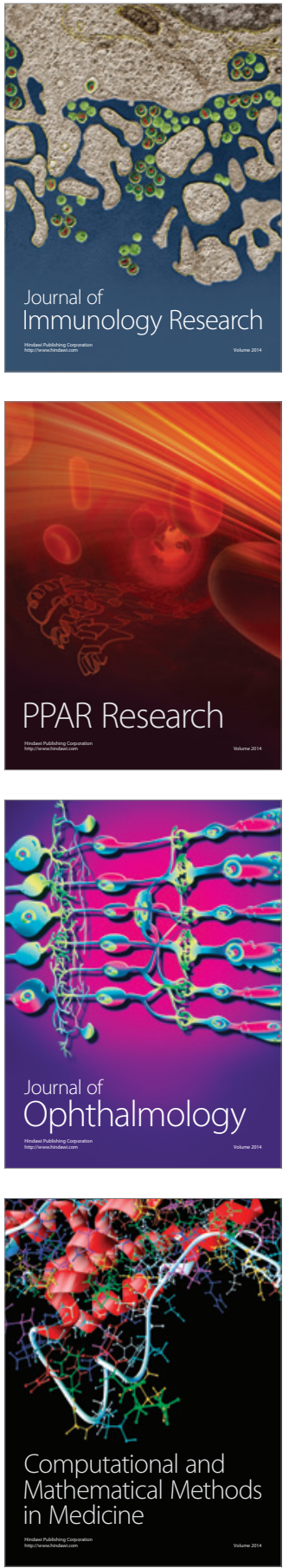

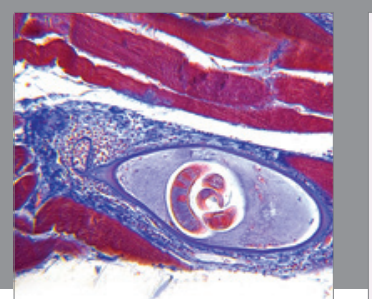

Gastroenterology Research and Practice

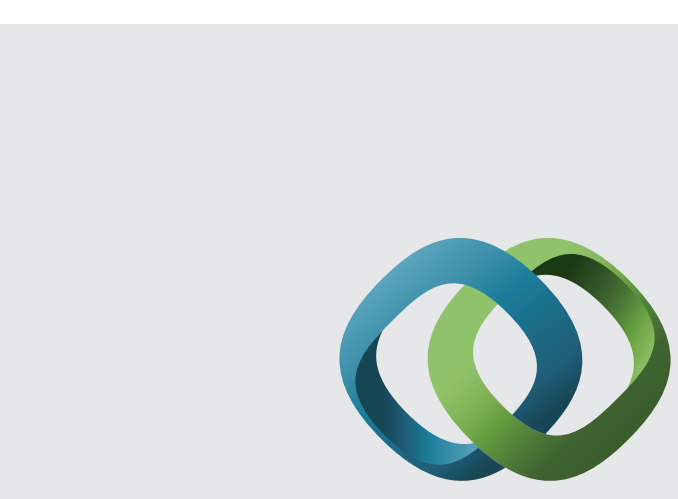

\section{Hindawi}

Submit your manuscripts at

http://www.hindawi.com
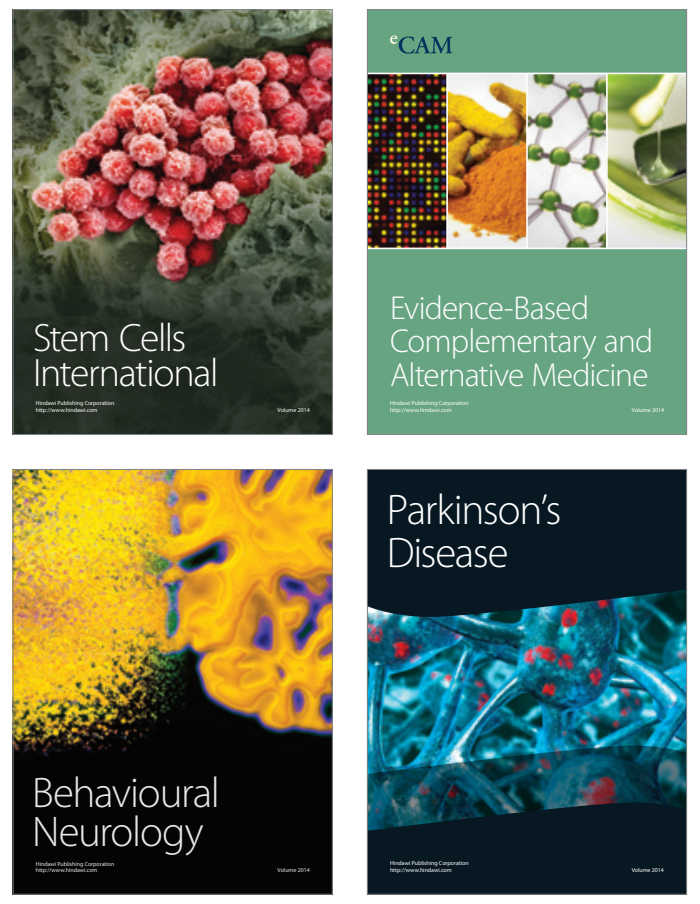
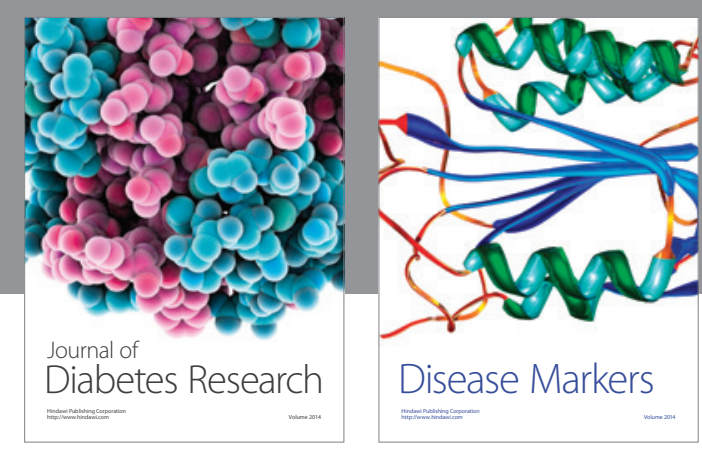

Disease Markers
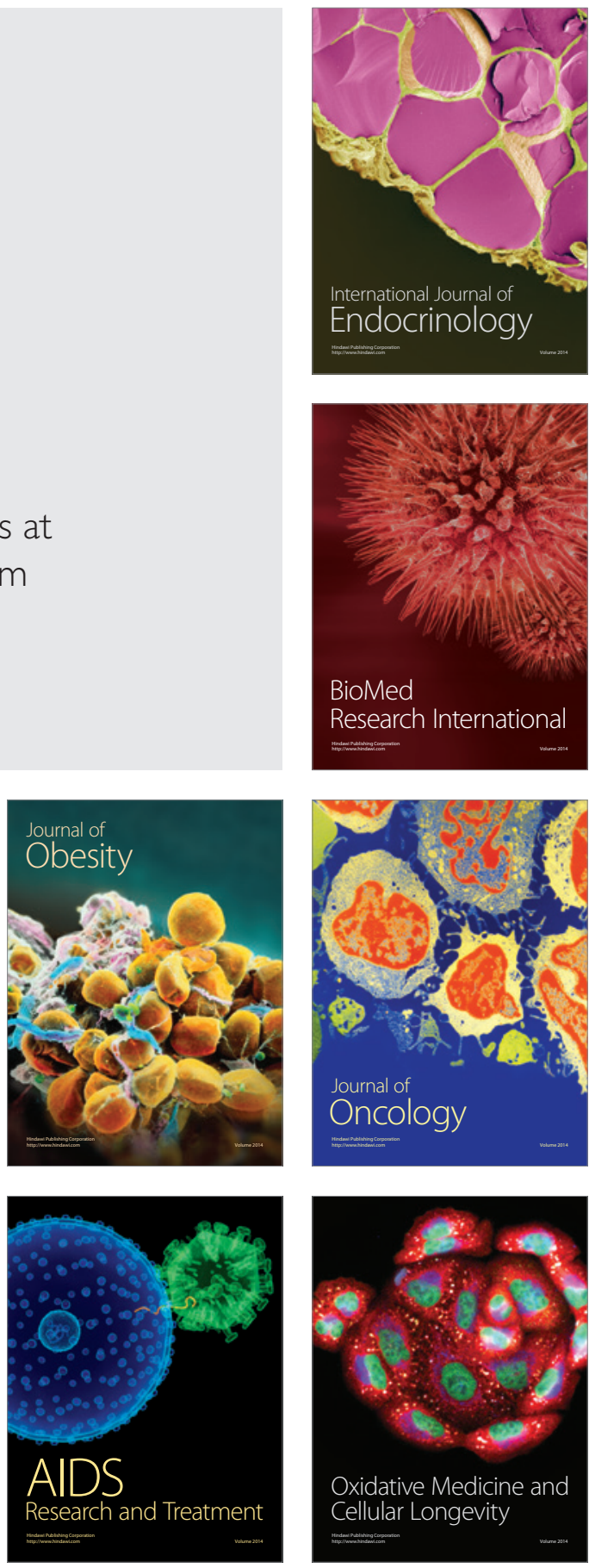